\title{
Article
}

\section{Organisational impact of the V150 nurse prescribing qualification}

Smith, Charlotte, Coucill, Catherine Anne and Nuttall, Dilyse Available at http://clok.uclan.ac.uk/23773/

Smith, Charlotte, Coucill, Catherine Anne and Nuttall, Dilyse ORCID: 00000002-0561-5229 (2018) Organisational impact of the V150 nurse prescribing qualification. British Journal of Community Nursing, 23 (8). pp. 370-375. ISSN 2052-2215

It is advisable to refer to the publisher's version if you intend to cite from the work. 10.12968/bjcn.2018.23.8.370

For more information about UCLan's research in this area go to http://www.uclan.ac.uk/researchgroups/ and search for < name of research Group>.

For information about Research generally at UCLan please go to http://www.uclan.ac.uk/research/

All outputs in CLoK are protected by Intellectual Property Rights law, including Copyright law. Copyright, IPR and Moral Rights for the works on this site are retained by the individual authors and/or other copyright owners. Terms and conditions for use of this material are defined in the policies page.

\section{CLoK}

Central Lancashire online Knowledge www.clok.uclan.ac.uk

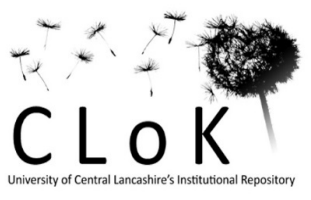


Title Sheet

Organisational Impact of the V150 Nurse Prescribing Qualification

Authors:

Charlotte Smith: Lecturer at University of Central Lancashire, School of Community Health and Midwifery

Cath Coucill: Senior Lecturer at University of Central Lancashire, School of Community Health and Midwifery

Dilyse Nuttall: Principal Lecturer at University of Central Lancashire, School of Community Health and Midwifery

Author responsible for correspondence:

Charlotte Smith

Csmith33@uclan.ac.uk

Tel: 01772893822 


\title{
Organisational Impact of V150 Nurse Prescribing Qualification
}

\author{
Abstract \\ Nineteen V150 prescribers from eight professional roles, and prescribing for a variety of \\ conditions, along with three Non-Medical Prescribing (NMP) Leads, participated in this \\ evaluation. An initial literature search identified a deficit in the NMP evidence base in relation \\ to V150 Community Practitioner Nurse Prescribing.
}

The evaluation used a mixed methodology of questionnaires and telephone interviews. Nineteen V150 prescribers participated, with all of them completing the online questionnaire. Two of these also consented to a follow-up telephone interview. Three NMP Leads completed the online questionnaire.

The findings suggested a benefit to the wider health organisation with regard to reduced attendance at Walk-in Centres, GP practices and A\&E. It is anticipated that the findings from this study may be prove useful to NMP Leads, NMP groups and commissioners as well as V150 prescribers.

Key words: V150, prescribing, evaluation, nurse prescribing

\section{Introduction}

This paper presents findings from an evaluation of V150 prescribing, commissioned by Health Education England North West. The purpose of the study was to examine NMP Leads' and V150 prescribers' perceptions of the impact of V150 prescribing on V150 prescribers, patients and organisations.

There is little reference to $\mathrm{V} 150$ prescribing in the current non-medical prescribing (NMP) evidence base. Much of the current NMP research uses a quantitative approach. As such, it 
does not address the V150 nurse prescribers' experiences and perception. This study seeks to address these gaps in knowledge by collecting data from and specific to, V150 Community Practitioner Prescribers, practising in NHS Trusts across the North West of England.

\section{The NMP Context}

A broad literature search on non-medical prescribing was undertaken after a refined search using the search term "V150" yielded no results. The literature provided information on the wider NMP context within which V150 prescribing sits.

A recent study undertaken by i5 Health, on behalf of NHS Health Education North West, identified a range of organisational benefits resulting from non-medical prescribing within the UK. Their report, titled "Non-Medical Prescribing: An Economic Evaluation" (NHS Health Education North West, 2015), identified how having a NMP practitioner within a practice setting can result in substantial cost savings. Earlier studies identified how the positive impact of NMP had realised the prediction of the Cumberlege Report by achieving high levels of satisfaction and trust from service users (Cox \& Walton, 1998; Courtenay \& Carey, 2005; Ersser, 2011).

Although the evidence base presents a benefit to organisations and individuals alike, there is evidence of inconsistency in the uptake of NMP training (Courtenay, 2013). One explanation for this is presented in a number of other studies which identify a range of organisational barriers to NMP, which include variations in the quality of supervision and mentorship as well as access to continuing professional development opportunities (Humphries \& Green, 2000; Cooper, Anderson, Avery, Bissell, Guillaume, Hutchinson, Lymn, Murphy, Ratcliffe and Ward; 2008). 


\section{uclän}

Aims:

- To investigate V150 prescribing activity in the North West region of England

- To identify the impact of V150 prescribing on NHS organisations

- To gather qualitative data on the V150 prescribers' experience

- To gain an understanding of the NMP Lead's role in relation to V150 prescribing

\section{Study Design}

\section{Method:}

The initial study proposal identified focus groups as the method for data collection. However, it proved difficult to recruit adequate numbers of participants to make this viable. It was thought most likely, based on feedback from practitioners, that this was due to work-based pressures limiting the time available to potential participants to attend.

In response, approval via the research change process was sought, to enable a mixed methods approach, using questionnaires and telephone interviews. A questionnaire for the V150 prescribers, including three key questions focussing on V150 prescribing activity and two questions focussing on the range of products and conditions for which V150 prescribers prescribe and resources to support prescribing, was developed. Participants who completed the questionnaire were invited to participate in a follow-up interview via telephone, using the same questions. A second questionnaire was developed for the NMP Leads, with questions focussing on their perceptions of the impact of V150 on the organisation and ways in which the impact could be improved. 


\section{uclân}

\section{Ethical considerations}

University and NHS research committee ethical approval was obtained for the study. Participants who agreed to be interviewed were asked to give written consent prior to their interview, using a consent form sent to them by email. It was made clear to participants both verbally and through the consent form that they could withdraw from the research project at any point.

\section{Inclusion criteria:}

Participation in the research project was dependent on practitioners within participating Trusts holding a V150 prescribing qualification. All participants worked in NHS settings across the North West of England.

\section{Data Collection:}

Data was gathered in the form of questionnaires, which were distributed, along with a participant information leaflet, by the Trusts' NMP Leads to all V150 prescribers within ten North West NHS Trusts. An advantage of questionnaires is that they can be distributed to large numbers (Bell, 2014); although a disadvantage is the inability to probe deeper into answers that participants have written (Streubert and Carpenter, 2011).

The V150 prescribing practitioners who participated represented four Trusts. No responses were received from the other six Trusts. Nineteen practitioners completed online questionnaires and two of these consented to telephone interviews. The quantitative and qualitative data collected was transcribed and analysed. A thematic analysis process was 
followed, using the method introduced by Brown and Clarke (2014), exploring themes and patterns that emerged from the data and these are reported on in the results section.

\section{Results}

Impact of V150 Nurse Prescribing on the organisation:

Out of the nurse prescribers who provided information, fifteen respondents identified their prescribing qualification and activities as having a positive impact on the wider Trust - see Fig.1 below.

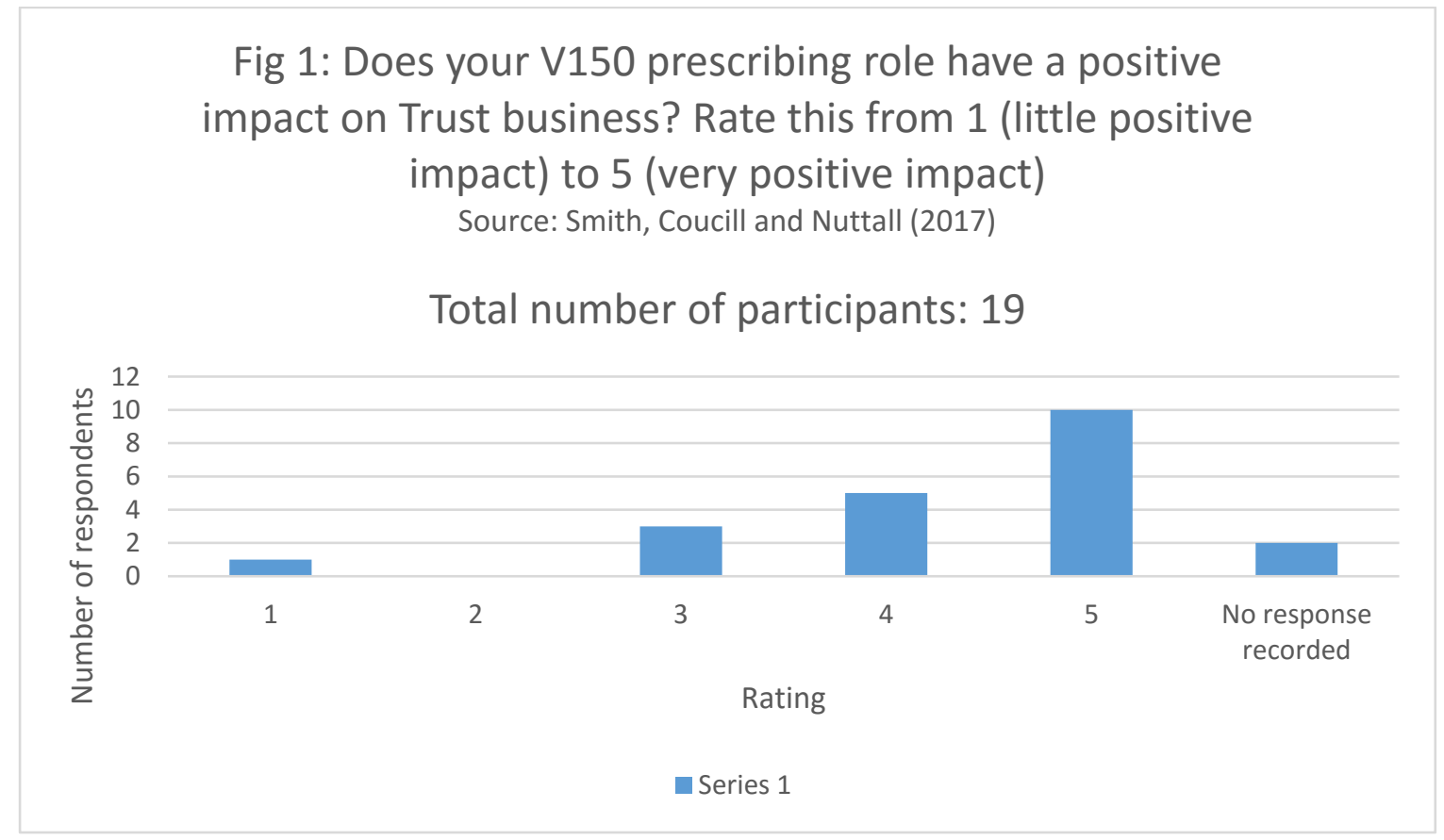

\section{i. Impact of V150 nurse prescribing on G.P. services and hospital admissions:}

Comments from prescribers imply a cost saving benefit to other members of the multidisciplinary team e.g. GP, in both appointments and time. A participant stated, "Prescribed treatment... can start sooner rather than waiting for a GP to complete a prescription" 


\section{uclân}

Another participant reported, "It means quicker access to items needed especially if it is near the weekend. Patients can access the prescription item quickly and do not have to wait over the weekend for a prescription from the GP"

This speed of treatment has the potential to save the NHS money as patients are assessed and treated in a timely manner. Fast treatment may negate a deterioration in condition and any extra costs this may have incurred.

"If I did not prescribe, the GP would have to issue prescriptions every time. We have expertise in the field - managing the condition well prevents patients getting infections - additional swelling - and keeps people in work/mobile/well." This implies nurse prescribing can contribute positively to a working economy.

There was also comment on the benefits of continuity of care "Prevents patients from having to go to practice nurse and prevents GP appointments." Improved continuity can also be achieved: "Reduces GP time as if we are completing prescriptions, it means they don't have to complete them. More continuity of care as we review our own treatment."

\section{ii. Impact of V150 nurse prescribing on A\&E, Walk-in Centres and hospital admissions:}

There is an inference that prescribing can reduce hospital admissions through the ability of nurse prescribers to deliver holistic, timely and preventative treatment. "It's more cost-effective to have [V150] prescribers. They can avoid patients going into hospitals, particularly if infections are spotted earlier..."

Along with a reduced demand on time from the wider NHS team, "It saves multiple practitioners having to assess patients in order to get a prescription." Also "Prevents patients from having to go to A\&E or Walk-in Centre" 
With limited resources and long waiting times in A\&E and Walk-in Centres reported, nurse prescribing potentially could increase capacity within the NHS along with patient satisfaction due to reduced waiting times for treatment.

\section{iii. Impact of V150 nurse prescribing on patients / clients and time saved:}

All respondents reported a positive response from patients and carers with regard to their ability to prescribe. Time saved for families is highlighted in these nurse prescriber's comments:

"When a patient receives a prescription during a visit they have the reassurance that this element of their care has been completed" and "Patients are able to take their prescription at their convenience and it offers a more efficient approach to care"

This time saved for families can be perceived as precious time:

"[patients] love it, particularly palliative patients - if they need products, there are issues already going on for that family, so they don't want the issue of trying to get in touch with the GP, trying to get a prescription from the GP... if we're there and we can do it alleviates some of the issues when they are already having a difficult time."

\section{iv. Impact of local policy on V150 nurse prescribing activity:}

Local decision-making has an impact on nurse prescribing, for example, one of the Trusts who participated in the research study, have recently adopted a new policy with regard to supply of dressings.

Dressings previously prescribed individually are now being stored in GP surgeries then practitioners take them directly to the patient: "GPs have stopped prescribing dressings at present and as a result we are keeping a stock of dressings at the base to take to patients 


\section{uclăn}

prior to the visit. I can still prescribe if it is an item not stocked, or if I need continence or skin care products."

One respondent suggested that this reduces nurse-prescribing capacity "I think with this new dressing's initiative people are prescribing less. I think we are using it less, which then has the issue that we are losing some of that confidence in your ability to prescribe. So I don't think that is helping prescribers who are actually prescribing less." This suggests local policy decisions may have wider impacts on prescribing.

\section{Non-Medical Prescribing (NMP) Leads' findings:}

NMP Leads from ten different Trusts received a questionnaire, from which three responded. Two of the three were from a nurse background holding prescribing qualifications, and one from a pharmacy background with no prescribing qualification. In total, the NMP leads who responded oversee three hundred and three V150 nurse prescribers.

\section{i. NMP Leads' contact with V150 prescribers:}

The NMP leads commented about the type of contact they had with V150 prescribers: one had "lots of contact for information, governance, databases, applications and prescribing issues" another had contact through "email prescribing data, cascade relevant medicines information and answer queries, viable at nursing bases." Another of the Leads meets face to face with prescribers regularly "on first qualification......we have quarterly District Nurse NMP meeting.... We have a DN NMP group email... a random sample of $15 \%$ of all prescribers submit for peer review."

\section{ii. Impact of V150 prescribing on Trust business:}

In response to the impact on Trust business, two NMP Leads reported a high impact from V150 nurse prescribing. A comment from one NMP Lead mirrors what the practitioners reported "enables practitioners to complete episodes of care. Save GP's time. Experts in the 


\section{uclan}

field are prescribing more appropriately therefore cost effective" These comments reflect the cost and time saving themes reported by V150 prescribers.

When asked about the resources available to support the NMP Leads' role, the two NMP Leads who have a prescribing qualification included peer and technical support "Trust leads Network, One to Ones, Regional Lead Network .... Senior Management Technician, administration support, IT and communications support to keep NMP intranet page updated." The NMP Lead from a pharmacy background not holding a prescribing qualification did not mention these resources, reporting, "As a pharmacist I can access most medicines resources directly and provide support and advice to NMP's in a timely manner. I also have access to prescribing data".

\section{iii. Maximizing the use of V150 prescribers in the organisation:}

The final area on which NMP Leads commented, was regarding what would maximise the use of a V150 qualification in their organisation. Each NMP Lead answered this question differently, including one with only one word "funding". Another NMP Lead cited "CPD for qualified leads e.g. medico-legal updates, prescribing influences, and wound care updates"

The remaining NMP Lead from a pharmacy background highlighted historical, financial and educational influences that appear to suggest a reduction in the benefits of the V150 nurse prescribing qualification. "The majority of prescribing historically is for wound management products" (this is not reflected in the V150 prescribers' findings). They go onto state "however local CCGs are now choosing to switch to Total Wound Purchase schemes which negate the need for FP10 prescriptions". A financial justification for the V150 qualification being less useful is then given "Also the NHS consultation on the use of items that can be purchased over the counter (OTC) may signify that a lot of products in the NPF become un-prescribable as patients will be expected to pay for them." Finally, an educational perspective is given, "I am aware that fewer universities are providing V150 courses, which I suspect is questioning this level of nurse prescribing in the future". 
There is caution about generalizing the findings as only three NMP Leads participated, making this a very small sample.

\section{Conclusions}

The research did identify some impact of $\mathrm{V} 150$ prescribing on the wider NHS services and organisations. Cost and time benefits identified by V150 prescribers included a reduction in time and appointments with GPs, in reduced hospital admissions and in less A\&E and Walkin Centre attendance. V150 prescribers also reported treatment being able to start sooner, leading to a reduction in complications and infections and keeping people mobile and working.

Benefits of V150 prescribing qualification, reported by prescribers in the research included: holistic appropriate care delivered in a timely manner with time saving benefits to patients and practitioners.

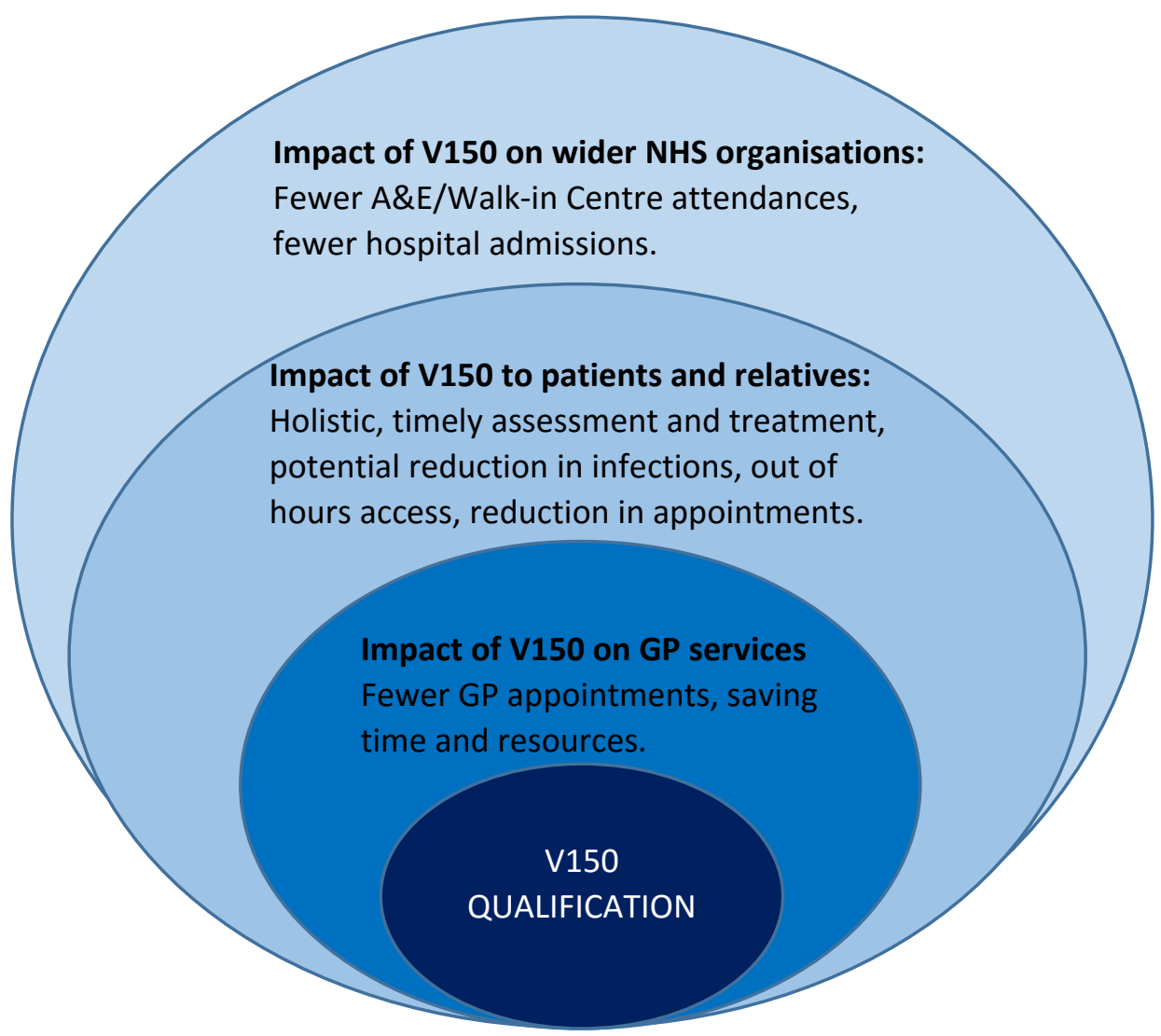

Figure 2: Organisational impact of V150 qualification 


\section{uclän}

\section{Potential bias:}

Except for one practitioner, only active V150 prescribers completed the questionnaires. Inclusion of V150 prescribers who did not use their prescribing qualification may have provided a clearer picture of V150 prescribing. It was recognised that as two of the researchers collecting and analysing the data was a lecturer in Non-Medical Prescribing, there may have been unconscious bias. To reduce the potential bias, a second researcher was selected who had no involvement in the prescribing programmes.

\section{Limitations}

Originally, it was proposed that focus groups would be used as it was expected that these would enable a richer data set to be gathered than would be possible by using online questionnaires. However, viability issues resulting from low numbers meant that this approach could not be used. An additional limitation related to the focus of the study being solely on the North West of England. The lack of inclusion of inactive V150 prescribers also placed limitations on the findings.

\section{Recommendations}

There are implications for policy and practice. Recent consultation around the inclusion of prescribing related content in pre-registration nursing education programmes and a V150 "type" of prescribing qualification for newly qualified nurses, has the potential to exponentially increase the cost and time benefits for organisations. Vastly increasing the number of NMP prescribers in practice will have implications for support and resources in practice, largely for the NMP Leads and this will need consideration. 
Suggestions for further research include targeting inactive V150 prescribers to identify the reasons for inactivity, and further exploration of the impact of policy such as stock dressings in primary care settings would also be useful.

The research findings could be useful to prescribing practitioners, commissioners, NMP Leads and members of the multi-disciplinary prescribing team such as GPs and pharmacists.

\section{References}

Bell, Judith (2014). Doing Your Research Project: A guide for researchers. McGraw-Hill Education (UK), 2014.

Bradley, E., \& Nolan, P. (2007). Impact of nurse prescribing: A qualitative study Journal of Advanced Nursing, 59(2), 120-128.

Braun, V. \& Clarke, V. (2014). What can thematic analysis offer health and wellbeing Researchers? International Journal of Qualitative Studies on Health and Well-being 9. ISSN 1748-2623 Available at: http://eprints.uwe.ac.uk/26537

Cooper, R. J., Lymn, J., Anderson, C., Avery, A., Bissell, P., Guillaume, L., Hutchinson, A., Murphy, E., Ratcliffe, J., and Ward, P. (2008) Learning to prescribe : Pharmacists' experiences of supplementary prescribing training in England BMC Medical Education 2008; 8: 57.

Courtenay, M. (2013). Interprofessional education between nurse prescribing and medical students: A qualitative study. Journal of Interprofessional Care, 27(1), 93-95. Available at: https://www.tandfonline.com/doi/full/10.3109/13561820.2012.724126

Courtenay, M., \& Carey, N. (2006). Nurse-led care in dermatology: A review of the literature. British Journal of Dermatology, 154(1), 1-6. Available at: https://onlinelibrary.wiley.com/doi/abs/10.1111/j.1365-2133.2005.06979.x

Cox, N. \& Walton, Y. (1998) Prescribing for out-patients by nursing staff in a dermatology department. British Journal of Dermatology, 139(1) 77-80 Available at: https://onlinelibrary.wiley.com/doi/abs/10.1046/j.1365-2133.1998.02317.x 
Department of Health and Social Security (1986) Neighbourhood Nursing: A Focus for Care (Cumberlege Report). London: HMSO

Ersser, S. J. (2011). Nurse prescribing, concordance and the therapeutic consultation. British Journal of Dermatology, 164(2), 236-237.

Humphries, J.L., and Green, E. (2000) Nurse prescribers: infrastructures required to support their role Nursing Standard 14 (48), 35-39.

NHS Health Education North West (2015) and i5Health (2015) Non-Medical Prescribing (NMP): An Economic Evaluation i5Health, NHS Education North West

Smith, C. Coucill, C. \& Nuttall, D. (2017) V150 Prescribing: "Perceptions and Experiences of the Impact of the V150 Qualification" Research Report. Available at: https://www.hecooperative.co.uk/nmp-zone/course-information/

Streubert, H. J. \& Carpenter, D. R. (2011). Qualitative research in nursing: Advancing the humanistic imperative. 5th ed. Philadelphia: Wolters Kluwer Health: Lippincott Williams \& Wilkins. 